\title{
Aus dem Vorwort zur 100.-106. Auflage
}

Die 1. Auflage dieses Buches erschien im Jahre 1892, also vor 60 Jahren. Es war ein schmales Bändchen von 176 Seiten, das seinem Begründer, dem Frankfurter Arzt Dr. Otto Dornblüth ausreichend erschien, um den Wortschatz der Medizin der Jahrhundertwende etymologisch und erläuternd darzustellen.

Die hiermit erscheinende 100. bis 106. Auflage umfaßt übèr 1050 Seiten, und man kann ohne Ǔbertreibung sagen, da $B$ fast täglich neue Begriffe hinzukommen.

Berlin, im September 1952

Willibald Pschyrembel

\section{Vorwort zur 107.-116. Auflage}

Aus technischen Gründen muß leider auch diese Auflage noch mit einem Nachtrag erscheinen. Fr wurde völlig neu bearbeitet und durch zahlreiche neue Begriffe aus der Diagnostik, Symtomatologie, Pharmakologie, Serologie und Operationstechnik ergänzt. Besonderen Dank für die Mitarbeit ist den Herren Dres Kern, Schlungbaum, Ernst Schmidt, Thiele und der med.techn. Assistentin Fräulein Kölling auszusprechen.

Berlin, im April 1955

Willibald Pschyrembel 